\title{
ABORDAGENS PEDAGÓGICAS NA FORMAÇÃO DO ENFERMEIRO GESTOR: CONCEPÇÃO DE DISCENTES INGRESSANTES
}

\author{
*Luciana Dantas Farias de ANDRADE ${ }^{1}$ \\ Sarah Coêlho de Araújo SilvaPORTO ${ }^{2}$ \\ Édija Anália Rodrigues de LIMA ${ }^{3}$ \\ Nathanielly Cristina Carvalho de Brito SANTOS ${ }^{4}$ \\ Maria Benegelania PINTO 5 \\ Heloisy Alves de MEDEIROS ${ }^{6}$
}

\begin{abstract}
${ }^{1}$ Enfermeira. Doutora em Psicologia. Professora da Unidade Acadêmica de Enfermagem - UAENFE, Universidade Federal de Campina Grande - UFCG, Cuité-PB, Brasil

${ }^{2}$ Bacharel em Enfermagem pela UFCG. E-mail: sarahcoelhotche@gmail.com

${ }^{3}$ Enfermeira.Mestre em Enfermagem pela Universidade Federal da Paraíba - UFPB. Docente da UAENFE, UFCG, Cuité - PB. E-mail: edijaprof@ hotmail.com

${ }^{4}$ Enfermeira.Doutoranda em Enfermagem pela UFPB. Docente da UAENFE, UFCG, Cuité - PB. Email:nathaniellycristina@gmail.com.

${ }^{5}$ Enfermeira.Doutoranda em Enfermagem pela Universidade Federal de Minas Gerais - UFMG. Docente na Universidade Federal de Pernambuco - UFPE, campus Vitória de Santo Antão -PE. E-mail: benegelania@yahoo.com.br

${ }^{6}$ Enfermeira.Doutoranda em Enfermagem pela UFMG. Docente da UAENFE, UFCG, Cuité - PB.E-mail: heloisymedeiros@hotmail.com

* Email para correspondência: luciana.dantas.farias@gmail.com
\end{abstract}

Recebido em: 05/08/2015 - Aprovado em: 04/01/2016 - Disponibilizado em: 30/07/2016

\begin{abstract}
Resumo
As abordagens pedagógicas adquirem papel prioritário na relação ensino-aprendizagemnas escolas de enfermagem pela responsabilidade em relação à formação, estímuloà reflexão e superaçãodos desafios cotidianos. Este estudo objetivou desvelar a contribuição das abordagens pedagógicas para a formação de discentes ingressantes do curso de Bacharelado em Enfermagem de uma instituição federal de ensino superior do nordeste brasileiro. Pesquisa descritiva, exploratória, com abordagem qualitativa, ancorada metodologicamente no Materialismo Histórico e Dialético (MHD). Os dados foram coletados através de entrevistas e processados pela técnica de análise de discurso proposta por Fiorin.Foi possível emergir a categoria analítica: $\mathrm{O}$ discente ingressante e seu contato com as abordagens pedagógicas do curso de enfermagem, e três categorias empíricas: 1. Disciplinas de identificação dos entrevistados; 2. Ênfase nos aspectos metodológicos do ensino e 3. Abordagem pedagógica dos docentes na visão discente.Foi possível constatar que a maioria dos discentes apontao uso de abordagens pedagógicas socioculturais em sala de aula, convergindo para uma formação acadêmica preocupada com o aspecto crítico e reflexivo desde o início da formação do enfermeiro gestor.

Palavras-chave:Educação Superior. Bacharelado em Enfermagem. Gestão em Saúde. Estudantes de Enfermagem. Docentes de Enfermagem.
\end{abstract}

\section{EDUCATIONAL APPROACHES IN TRAINING NURSE MANAGER: OF STUDENTS ENTERING DESIGN}

\begin{abstract}
Pedagogical approaches acquire a priority role in the teaching-learning in nursing schools the responsibility for training, stimulating reflection and overcoming daily challenges. This study aimed to reveal the contribution of pedagogical approaches to training students entering the Bachelor of Nursing course of a federal institution of higher education in northeastern Brazil. Descriptive, exploratory study with a qualitative approach, anchored in methodologically Historical and Dialectical Materialism (MHD). Data were collected through interviews and processed by the speech analysis technique proposed by Fiorin. Could emerge analytical category: The newcomer students and their contact with pedagogical approaches the nursing program, and three empirical categories: 1. Disciplines identification of respondents; 2. Focus on methodological aspects of teaching and 3. Pedagogical approach of teachers in student view. It
\end{abstract}


was found that most of the students says the use of socio-cultural pedagogical approaches in the classroom, converging to a concerned academic background with the critical and reflective aspect since the formation of the nurse manager.

Keywords: Education, Higher.Education, Nursing, Baccalaureate.Health Management.Students, Nursing.Faculty, Nursing.

\section{Introdução}

O papel da gerência em enfermagem tem o objetivo de organizar o processo de trabalho e os recursos humanos, trabalhando com um conjunto de instrumentos como planejamento, dimensionamento de pessoal, recrutamento, educação continuada, controle de materiais, equipamentos e saberes administrativos (FERNANDES, 2004).

Nesse âmbito, elucida-se a importância da formação acadêmica do enfermeiro gestor como algo abrangente, complexo, contínuo e criativo, por isso, para atuar nesse cenário é preciso ter, além de conhecimentos atualizados contextualizados, um olhar constantemente dirigido para as práticas historicamente constituídas (NIMTZ; CIAMPONE, 2006).

Desta maneira, toda situação didática, por mais simples que possa parecer, é complexa e o método de ensino torna-se concreto quando se converte em método de aprendizagem. Assim, o uso de tecnologias instrucionais devemfazer parte do processo educacional em sua multidimensionalidade e toda e qualquer estratégia tem importância fundamental no processo, uma vez que é o vínculo que se pretende com o processo educacional (CIAMPONE; KURCGANT, 2004).
Neste contexto, esta pesquisa enfatizaos postulados da professora Mizukami (1986) que revela que algumas abordagens pedagógicas, entendidas como processos de ensino e avaliação,apresentam claro referencial filosófico e psicológico, ao passo que outras são intuitivas ou fundamentadas na prática, ou na imitação de modelos. A autora classifica o processo de ensino e avaliação nas seguintes abordagens pegagógicas: tradicional, comportamentalista, humanista, cognitivista e sociocultural.

Deste modo, os conhecimentos adquiridos no decorrer do curso de enfermagem se tornam instrumentos que permitem aos alunos atuarem sobre o objeto de trabalho para transformá-lo em direção à finalidade almejada (GRECO, 2004).

Esta pesquisaconstitui um subprojeto do projeto "Formação do enfermeiro gestor: limites e possibilidades das práticas educativas no ensino superior", vinculado ao Programa Institucional de Bolsas deiniciação científica(PIBIC) em articulação com o curso de Bacharelado em Enfermagem da Unidade Acadêmica de Enfermagem do Centro de Educação e Saúde da Universidade Federal de Campina Grande.

Diante da necessidade de promover melhorias na gestão em enfermagem no âmbito dos serviços de saúde, justifica-se a 
realização deste estudotendo em vista o aperfeiçoamento da construção do perfil do enfermeiro gestor, conforme Resolução CNE/CES $n^{\circ}$. 03/2001, desde o ingresso do discente na Instituição de Ensino Superior, viabilizando o seguinte questionamento: o processo ensino-aprendizagem do curso de enfermagem de uma instituição nordestina de ensino superior está utilizando abordagens pedagógicas que promovam a formação do enfermeiro gestor, desde o seu ingresso, conforme a Resolução CNE/CES nº. 03/2001?

Neste sentido, objetiva-se desvelar a contribuição das abordagens pedagógicas para a formação do enfermeiro gestor no início do curso, através da visão de discentes ingressantes do curso de Bacharelado em Enfermagem de uma instituição federal de ensino superior do nordeste brasileiro.

\section{Material e Métodos}

$\mathrm{O}$ referencial metodológico que sustenta esta pesquisa é o Materialismo Histórico e Dialético (MHD), que foi elaborado em meados do século XIX por Marx (1818-1883) e Engels (1820-1895), na tentativa de buscar explicações coerentes, lógicas e racionais para os fenômenos da natureza, da sociedade e do pensamento (TRIVIÑOS, 2009).

A presente pesquisa foi do tipo descritiva e exploratória com abordagem qualitativa realizada na Universidade Federal de Campina Grande/Centro de Educação e Saúde (CES), campus Cuité-PB.

Foram convidados a participar do estudo, seis (6) discentes do segundo e terceiro períodos, de um total de 10períodos, do Curso de Bacharelado em Enfermagem, da Universidade Federal de Campina Grande, campus Cuité-PB.

Para coleta dos dados, foi utilizado um roteiro semiestruturado para fundamentar a entrevista, com três (3) perguntas abertas dirigidas aos discentes ingressantes de enfermagem, a partir das respostas, foram identificados os posicionamentos dos estudantes acerca da contribuição das abordagens pedagógicas utilizadas pelos docentes, principalmente em disciplinas relacionadas à formação do enfermeiro gestor.

Os sujeitos foram identificados pela inicial maiúscula "E" seguido da sequência cronológica da realização das entrevistas. Não foi associado o entrevistado ao período em que estava cursando, a fim de garantir seu anonimato.

Foi feita uma abordagem com discentes do $2^{\circ}$ e $3^{\circ}$ períodos do curso de bacharelado em enfermagem e, após aprovação do projeto no comitê de ética e do aceite do sujeito em realizar a entrevista, houve o convite para um encontro pessoal envolvendo pesquisadora e entrevistado em um ambiente previamente agendado e que permitiu a gravação do áudio em aparelho 
gravador, garantindo maior veracidade das informações colhidas.

As entrevistas gravadas foram transcritas logo a seguir, sendodada ao entrevistado a garantia do anonimato e do direito de desistir durante qualquer momento da pesquisa, conforme preconiza a Resoluçãon ${ }^{\circ} .466 / 2012$ que trata da pesquisa envolvendo seres humanos.

O período da realização da coleta dos dados foi no mês de novembro e dezembro de 2013 e fevereiro de 2014, após análise e aprovação do comitê de ética em pesquisa com seres humanos, através do parecer $\mathrm{n}^{\circ}$ 397.483 de 12 de setembro de 2013.

A análise dos dados coletados foi realizada através da técnica de análise de discurso proposta por Fiorin (2005), pois se trata de uma técnica indicada para pesquisas qualitativas, principalmente quando esta é ancorada pelo MHD. O autor mencionado esboça as características entre discurso e texto e as exemplifica enunciando que o discurso é determinado pela concretização das concepções ideológicas.

O princípio básico dessa análise é, diante de um texto onde tudo parece mais ou menos disperso, saber reconhecer o nível mais abstrato (temático) que lhe dá coerência(FIORIN, 2005).

A partir dos depoimentos dos participantes foi feita a depreensão dos temas principais que foram agrupados em blocos de significação que originaram a categoria analítica e categorias empíricas, sendo analisadas em articulação com a literatura pertinente.

\section{Resultados e discussão}

O estudo foi realizado com seis (6) estudantes de enfermagem do sexo feminino e masculino, na faixa etária envolvendo dezoito (18) à vinte e oito (28) anos, que cursavam o $2^{\circ}$ e $3^{\circ}$ períodos do curso de enfermagem.

Tabela 1: Seleção das categorias

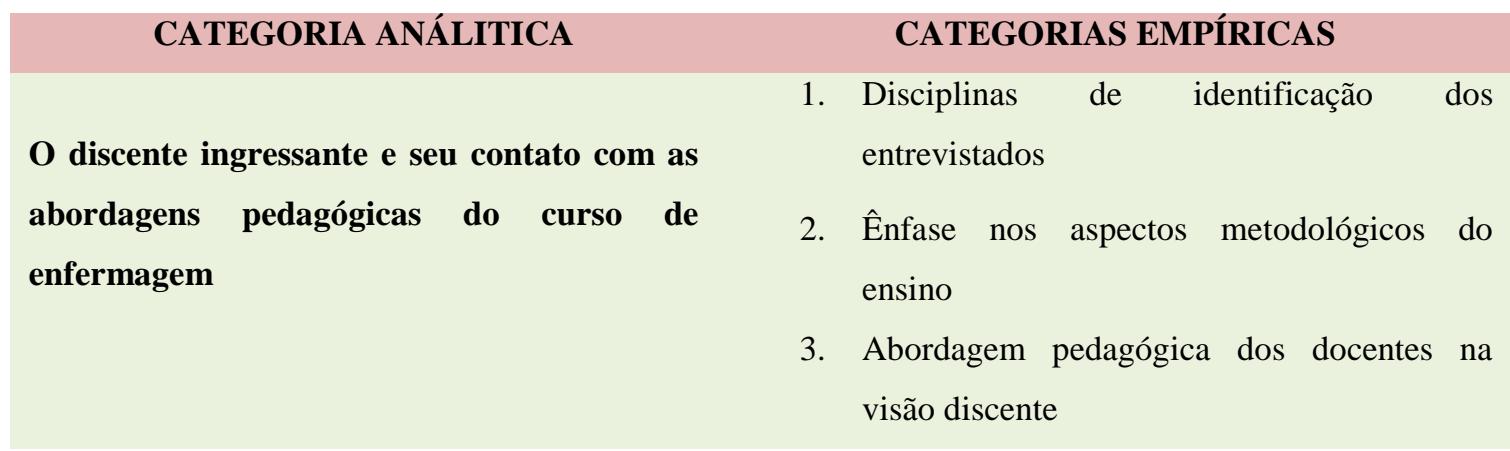

Fonte: Dados da pesquisa: 2014

Tendo a finalidade de atingir os objetivos da pesquisa, foi possível alcançar o nível mais abstrato, de concepção ideológica, através dacategoria analítica: $O$ discente ingressante e seu contato com as 
abordagens pedagógicas do curso de enfermagem, oriunda das três categorias empíricas provenientes da transcrição e interpretação das falas dos entrevistados:1. Disciplinas de identificação dos entrevistados;2.Ênfase nos aspectos metodológicos do ensino e 3. Abordagem pedagógica dos docentes na visão discente.

\subsection{Disciplinas de identificação dos entrevistados}

Com a análise da ótica dos discentes, pode ser visto que todos incluíram pelo menos uma disciplina específica da enfermagem nas matérias de maior identificação. Os alunos expressaram suas preferências pelas disciplinas: "Farmacologia $e$ semiologia” (E1); “Atualmente eu estou gostando mais de semiologia... farmacologia também estou gostando, aprendendo novas coisas, descobertas, assim, descobrindo as medicações, as ações de cada medicamento, o que é que pode e o que é que não pode (pausa) também está sendo bom” (E2); "Semiologia e saúde coletiva" (E3); “É... com saúde coletiva I e seminário integrador, como também com farmacologia” (E4); "Eu me identifico com patologia, semiologia $e$ farmacologia” (E5); “As que eu mais me identifico... patologia, eu gosto muito. Fisiologia, gostei muito, anatomia também, bioquímica..."(E6).

O termo disciplina especifica uma categoria organizadora dentro do conhecimento científico, partindo sempre de ideias prévias e conhecimentos práticos a respeito de um determinado tema (PIRES, 2009).

As falas e a análise do material empírico permitem identificar que os alunos ingressantes se direcionam mais para as disciplinas que remetem a procedimentos técnicos em enfermagem.

Freire (2011) destaca que o educando necessita buscar conhecimento além do que é repassado pelo educador. Afirmando, assim, a limitação do aluno na busca de conhecimentos além do programado.

Deste modo, a análise criteriosa dos depoimentos dos ingressantes do Curso de Enfermagem converge para a valorização de disciplinas de cunho tecnicista em detrimento às disciplinas que ampliam este conhecimento, principalmente no tocante à formação do enfermeiro gestor.

Como as disciplinas de “administração e gestão em serviços de saúde I" e "administração e gestão em serviços de saúde II” só serão 
ministradas a partir do $5^{\circ}$ período,disciplinas como semiologia e semiotécnica, patologia, anatomia não discutem diretamente a gestão em enfermagem, embora saúde coletiva conduza à necessidade de gestão da saúde considerada a gênese das discussões envolvendo administração, juntamente com a disciplina ética, bioética e legislação em enfermagem.

\section{2. Ênfase nos aspectos metodológicos do ensino}

A metodologia de ensino pode ser definida como o estudo dos métodos que são traçados e planejados pelo educador, para orientar e direcionar o processo ensino-aprendizagem.

No processo pedagógico estabelecem-se objetivos, conteúdos e métodos, contudo, a assimilação deles é consequência da atividade mental dos alunos. $\mathrm{O}$ ensino crítico envolve tarefas de ensino-aprendizagem encaminhadas no sentido de formar convicções, princípios orientadores da atividade prática humana frente a problemas $\mathrm{e}$ desafios da realidade social (FARIAS; SILVA, 2008).

A análise da pesquisa mostra o prisma dos discentes referente aos aspectos metodológicos utilizados pelos docentes no campo da pesquisa em questão: "Bom, eles são mais dinâmicos. Porque é tanto como a professora de 'ética', que ela está fazendo seminários, ela está procurando passar de maneira melhor para a gente, já que quando se refere à administração e leis é mais complicado o aluno aprender, né?! De memorizar. Porque não é só você decorar, tem que aprender. Como ela faz essas coisas, como os professores fazem, fica mais fácil a gente assimilar o assunto”(E2).

Nota-se que o conceito de metodologia de ensino abarca a prática de qualquer educador, sendo este conservador ou emancipador. De acordo com a Resolução CES/CNE n 03/2001, que institui asDiretrizes Curriculares Nacionais do curso de Enfermagem, o docente deve implementar metodologias no processo ensino-aprendizagem que estimule o aluno a refletir sobre a realidade social e aprenda a aprender, ou seja, propor métodos de ensino que facilitem a aprendizagem.

No caso da disciplina "ética, bioética e legislação em enfermagem”, devido ao grande arcabouço teórico, quanto mais forem ofertadas atividades dinâmicas que aproximem do real, melhor para a compreensão dos alunos. "É, geralmente é uma aula normal em slide, de vez em quando eles 
tentam inovar, fazendo júri simulado, mesa redonda, até mesmo peça de teatro, fantoche, essas coisinhas, eles também usam”(E5).

Uma concepção tradicional de educação enxerga na metodologia de ensino um artifício para ensinar tudo a todos, de forma lógica, inteligente e desenvolvida, sendo um conjunto de procedimentos destinado a transmitir todo e qualquer conhecimento universal e sistematizado. Segundo Mizukami (1986), a abordagem tradicional trata-se de uma concepção e uma prática educacional, onde o ensino é centrado no professor. O aluno apenas executa prescrições que lhe são fixadas por autoridades exteriores.

$\mathrm{O}$ professor, considerado $\mathrm{o}$ elemento mediador do processoensinoaprendizagem, tem influência direta nas situaçõesque ocorrem em sala de aula, no relacionamentoaluno/professor, no planejamento e adequação das condiçõesde aprendizagem e no relacionamento com os demais docentes (NIMTZ; CIAMPONE, 2006).

Pelos depoimentos pode-se deduzir que o professor que prepara o futuro enfermeiro gestor preocupa-se em implementar metodologias que estimule a refletir sobre a realidade social e aprenda a aprender.

\subsection{Abordagem pedagógica dos docentes na visão discente}

Os discentes classificaram os professores em dois extremos: professores com abordagem pedagógica de caráter sociocultural ou abordagem pedagógica tradicional, de acordo com os processos de ensino e avaliação utilizados pelos mesmos.

Os discentes, quando questionados sobre o posicionamento dos docentes quanto ao caráter sociocultural ou tradicional, mostram objetividade em suas respostas: “Ah, são mais dinâmicos. Porque sempre acabam trazendo novidades, eles sempre trazem alguma novidade que possa chamar a atenção do aluno" (E2).

A análise reflexiva das falas dos entrevistados revela que a característica dinâmica dos docentes tende ao uso da abordagem sociocultural. Esta visa comprometer osalunos com problemas de seu ambiente. A relação professor aluno é horizontal e não imposta, onde ambos aprendem e ensinam; o docente deve criar, junto com os discentes, condições para a percepção e discussão dascontradições da sociedade da qual eles fazem parte.

Contrário a esta postura, "Tem alguns tradicionais que é só leitura dos 
slides e você entenda lá na leitura deles, mas, tem aqueles que fazem de uma forma dinâmica e diferente para você entender o assunto"(E3).

Mizukami(1986) afirma que a escola deve ser um local onde seja possível o crescimento mútuo, do professor e dos alunos. A situação de ensino-aprendizagem deverá procurar a superação da relação opressor-oprimido. A estrutura de pensar do oprimido está condicionada pela contradição vivida na situação concreta, existencial em que o oprimido se forma.Nesta situação, a relação professor-aluno é horizontal, sendo que o professor se empenhará numa prática transformadora que procurará desmitificar e questionar, junto com o aluno.

De acordo com a análise, é possível notar uma divisão de opiniões entre os entrevistados quanto à caracterização dos docentes diante das abordagens pedagógicas utilizadas pelos mesmos. "Mais tradicionais, a maioria, são poucos que estão inovando o ensino, por enquanto"(E5); "Tradicionais!" (E6); "Porque?" (ENTREVISTADOR); "Pelo método da aula, pela utilização somente dos slides e leitura"(E6).

Segundo Mizukami (1986), a abordagem tradicional trata-se de uma concepção e uma prática educacional, onde o ensino é centrado no professor. Evidencia-se o caráter cumulativo do conhecimento humano, adquirido pelo indivíduo por meio de transmissão, de onde se supõe o papel importante da educação formal e da instituição escolar.Ao indivíduo que está "adquirindo" conhecimento compete memorizar definições, anunciando leis, sínteses e resumos que lhes são oferecidos no processo de educação formal.

Assim, temos o método expositivo, que é utilizado como atividade didática principal na transmissão de conceitos e informações, o professor detém o controle decisório da ação educativa e o aluno é um ser passivo nesse processo; a avaliação é realizada por meio de provas e exames que visam à reprodução do conteúdo comunicado

(VENDRÚCOLO;

MANZOLLI, 1996).

\section{Conclusão}

A formação acadêmica do enfermeiro deve ser transformadora e emancipatória, onde os docentes utilizem abordagens pedagógicas sócioculturaisem seus processos de ensino e avaliação, tornando cidadãos reflexivos, críticos e questionadores. 
Durante o curso de Bacharelado em Enfermagem é necessário que haja motivação na inter-relação professoraluno, pois, seus reflexos influenciam diretamente o processo de formação do futuro enfermeirogestor.

$$
\text { Entende-se que a educação }
$$
constituio pilar da transformação dos paradigmas sociais e humanos, podendo promover mudanças na forma de sentir, pensar e atuar das pessoas em relação a si mesmas e aos outros. Desta forma, o processo ensino-aprendizagem possibilita ao indivíduo sair da rotina de conhecimentos e buscar novas formas de saber, interpretar e aprender.

Ao longo dessa pesquisa, foi possível perceberdivergênciasnas opiniões dos discentes entrevistados em relação às abordagens pedagógicas utilizadas pelos docentes em sala de aula, principalmente em disciplinas de cunho administrativo, mais precisamente na disciplina "ética, legislação e bioética em enfermagem", citada nas entrevistas. Contudo, a maioria das repostas levaram à caracterização dos docentes como utilizadores da abordagem sociocultural, superandoformas tradicionais para buscar novas estratégias reflexivas e emancipatórias.
Embora os professores estejam motivados para trazer as abordagens pedagógicas socioculturais para $\mathrm{o}$ cotidiano acadêmico, certas atividades desenvolvidas ainda demonstram características tradicionais, através das aulas expositivas, com leituras não críticas, além de avaliações através de provas, o que justifica o posicionamento de alguns discentes que caracterizaram os docentes como tradicionais.

\section{Referências}

BRASIL. Ministério da Saúde. Conselho Nacional de Saúde.

Resolução CNS no 466, de 12 de dez de 2012. Diretrizes e normas regulamentadoras de pesquisas envolvendo seres humanos. Diário Oficial da Oficial da União. Brasília, DF: Ministério da Saúde, 2012. Ministério da Educação. Conselho Nacional de Educação. Câmara de Educação Superior. Resolução CNE/CES nº 03, de 07 de novembro de 2001. Institui Diretrizes Curriculares Nacionais do Curso de Graduação em Enfermagem. Disponível em:

$<$ http://www.anaceu.org.br/legislacao/re solucoes/reso3_07-11-2001.html>. Acesso em: 11 dez. 2013.

CIAMPONE, M. H. T.; KURCGANT, P. O ensino de administração em enfermagem no Brasil: o processo de construção de competências gerenciais.

Rev. Bras Enferm, Brasília (DF), v. 57, n. 4, p. 401-7, jul./ago. 2004.

FARIAS, L. D.; SILVA, C. C. Administração em Enfermagem: 
desvelando as bases conceituais, metodológicas e pedagógicas de seu ensino em João Pessoa - PB. Cienc

Cuid Saude, v. 7, n. 1, p. 37-44, jan./mar. 2008.

FERNANDES, C. N. S. Refletindo sobre o aprendizado do papel de educador no processo de formação do enfermeiro. Rev. latino-am. Enferm, Ribeirão Preto, v. 12, n. 4, p. 691-3, jul./ago. 2004.

FIORIN, J. L. Elementos de análise de discurso. 13. ed. São Paulo: Contexto, 2005.

FREIRE, P. Pedagogia do

Oprimido.São Paulo: Vozes, 2011.

GRECO, R. M. Relato de experiência: ensinando a administração em enfermagem através da educação em saúde.Rev. Bras Enferm, Brasília (DF), v. 57, n. 4, p. 504-7, jul./ago. 2004.

MIZUKAMI, M. G. N. Ensino: as abordagens do processo. São Paulo: EPU, 1986.

NIMTZ, M. A.; CIAMPONE, M. H. T. O significado de competência para o docente de administração em enfermagem. Rev Esc Enferm USP, v. 40, n. 3, p. 336-42, 2006.

PIRES, D. A enfermagem enquanto disciplina, profissão e trabalho. Rev. Bras Enferm, Brasília (DF), v. 62, n. 5, p. 739-44, set./out. 2009.

TRIVIÑOS, A. N. S. Bases teóricometodológicas da pesquisa qualitativa em ciências sociais. Cad de Pesquisa, v. 4, n.1, p. 73-106, 2009.

VENDRÚSCOLO, D. M. S.;

MANZOLLI, M. C. O currículo na e da enfermagem: por onde começar e recomeçar. Rev. latino-am. Enferm, Ribeirão Preto, v.4, n. 1, p. 55-70, jan. 1996. 